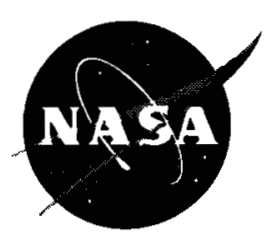

Performance Expectations of Closed-Brayton-Cycle Heat Exchangers in 100-kWe Nuclear Space Power Systems

Michael J. Barrett

Glenn Research Center, Cleveland, Ohio 
Since its founding, NASA has been dedicated to the advancement of aeronautics and space science. The NASA Scientific and Technical Information (STI) Program Office plays a key part in helping NASA maintain this important role.

The NASA STI Program Office is operated by Langley Research Center, the Lead Center for NASA's scientific and technical information. The NASA STI Program Office provides access to the NASA STI Database, the largest collection of aeronautical and space science STI in the world. The Program Office is also NASA's institutional mechanism for disseminating the results of its research and development activities. These results are published by NASA in the NASA STI Report Series, which includes the following report types:

- TECHNICAL PUBLICATION. Reports of completed research or a major significant phase of research that present the results of NASA programs and include extensive data or theoretical analysis. Includes compilations of significant scientific and technical data and information deemed to be of continuing reference value. NASA's counterpart of peerreviewed formal professional papers but has less stringent limitations on manuscript length and extent of graphic presentations.

- TECHNICAL MEMORANDUM. Scientific and technical findings that are preliminary or of specialized interest, e.g., quick release reports, working papers, and bibliographies that contain minimal annotation. Does not contain extensive analysis.

- CONTRACTOR REPORT. Scientific and technical findings by NASA-sponsored contractors and grantees.
- CONFERENCE PUBLICATION. Collected papers from scientific and technical conferences, symposia, seminars, or other meetings sponsored or cosponsored by NASA.

- SPECIAL PUBLICATION. Scientific, technical, or historical information from NASA programs, projects, and missions, often concerned with subjects having substantial public interest.

- TECHNICAL TRANSLATION. Englishlanguage translations of foreign scientific and technical material pertinent to NASA's mission.

Specialized services that complement the STI Program Office's diverse offerings include creating custom thesauri, building customized databases, organizing and publishing research results ... even providing videos.

For more information about the NASA STI Program Office, see the following:

- Access the NASA STI Program Home Page at http://www.sti.nasa.gov

- E-mail your question via the Internet to help@sti.nasa.gov

- Fax your question to the NASA Access Help Desk at 301-621-0134

- Telephone the NASA Access Help Desk at $301-621-0390$

- Write to: NASA Access Help Desk NASA Center for AeroSpace Information 7121 Standard Drive Hanover, MD 21076 


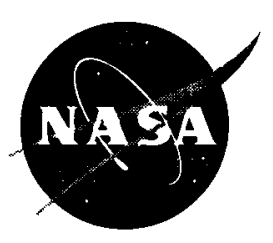

\section{Performance Expectations of Closed-Brayton-Cycle Heat Exchangers in 100-kWe Nuclear Space Power Systems}

Michael J. Barrett

Glenn Research Center, Cleveland, Ohio

Prepared for the

First International Energy Conversion Engineering Conference sponsored by the American Institute of Aeronautics and Astronautics

Portsmouth, Virginia, August 17-21, 2003

National Aeronautics and

Space Administration

Glenn Research Center 


\title{
Acknowledgments
}

Support for this work was received from the Office of Space Science (Code S) at NASA Headquarters.

This report contains preliminary

findings, subject to revision as analysis proceeds.

$$
\text { analysis proceeds. }
$$

\author{
-
}




\title{
PERFORMANCE EXPECTATIONS OF CLOSED-BRAYTON-CYCLE HEAT EXCHANGERS IN 100-kWe NUCLEAR SPACE POWER SYSTEMS
}

\author{
Michael J. Barrett \\ National Aeronautics and Space Administration \\ Glenn Research Center \\ Cleveland, Ohio 44135 \\ E-mail: Michael.J.Barrett@nasa.gov
}

\begin{abstract}
Performance expectations of closed-Brayton-cycle heat exchangers to be used in $100-\mathrm{kWe}$ nuclear space power systems were forecast. Proposed cycle state points for a system supporting a mission to three of Jupiter's moons required effectiveness values for the heat-source exchanger, recuperator and rejection exchanger (gas cooler) of $0.98,0.95$, and 0.97 , respectively. Performance parameters such as number of thermal units $(\mathrm{Ntu})$, equivalent thermal conductance $(U A)$, and entropy generation numbers $(N s)$ varied from 11 to 19,23 to $39 \mathrm{~kW} / \mathrm{K}$, and 0.019 to 0.023 for some standard heat exchanger configurations. Pressure-loss contributions to entropy generation were significant; the largest frictional contribution was $114 \%$ of the heattransfer irreversibility. Using conventional recuperator designs, the 0.95 effectiveness proved difficult to achieve without exceeding other performance targets; a metallic, plate-fin counterflow solution called for $15 \%$ more mass and $33 \%$ higher pressure-loss than the target values. Two types of gas-coolers showed promise. Single-pass counterflow and multipass crosscounterflow arrangements both met the 0.97 effectiveness requirement. Potential reliability-related advantages of the cross-counterflow design were noted. Cycle modifications, enhanced heat transfer techniques and incorporation of advanced materials were suggested options to reduce system development risk. Carboncarbon sheeting or foam proved an attractive option to improve overall performance.
\end{abstract}

\section{INTRODUCTION}

Safe nuclear energy conversion is an enabling technology for enhanced science missions to the outer planets ${ }^{1}$ where power and propulsion systems using solar power are hindered by low solar energy flux. The energy provided by a small fission reactor will allow science instruments to rapidly transmit large blocks of information to earth using data transmission rates and bandwidth unattainable using batteries, solar collectors, or arrays of solar (photovoltaic) cells. A fissionpowered electric propulsion system will allow a spacecraft to visit multiple locations in a planetary system without relying on gravity-assist trajectories that lead to only short-term "fly-bys" of a planet or its moons. Once in orbit, the energy available in a fission reactor will allow extended science observations over longer durations than those currently possible using other energy sources. The recognition recently awarded these benefits of space nuclear power has revived interest in energy conversion technologies that convert a fission reactor's thermal energy into electrical energy useful to spacecraft science instruments and electric propulsion systems.

There are numerous energy conversion options. One that shows promise in attaining safe and reliable operation, high system-level efficiencies, and flexible scalability in power level is a dynamic power conversion system using a closed-Brayton-cycle (CBC) heat engine. To reduce the engine mass, thermal energy is converted to electrical work using an alternator that is integrated with the compressor and turbine on a single rotating assembly - a turboalternator compressor (TAC) ${ }^{2}$ A generic temperature-entropy diagram of a recuperated $\mathrm{CBC}$ is presented in Fig. 1. The diagram shows that three heat exchangers are essential components in the recuperated $\mathrm{CBC}$ engine systemthe heat source heat exchanger (HSHX), the recuperator, and the gas cooler (GC). In a $100-\mathrm{kWe}$ class CBC space power conversion system (PCS), the expectations of the heat exchangers can be demanding. Quantified performance analyses are needed to assess the feasibility of different system configurations.

The present work introduces an operating state point reference for a $100-\mathrm{kWe}$ CBC PCS. With the system state points established, sizing and performance parameters are presented for standard heat exchanger configurations used in the three exchanger roles identified. Then, the recuperator is used as an example to compare current performance expectations to

AIAA Senior Member, Research Engineer, Thermo-Mechanical Systems Branch, Power and On-Board Propulsion Technology Division 


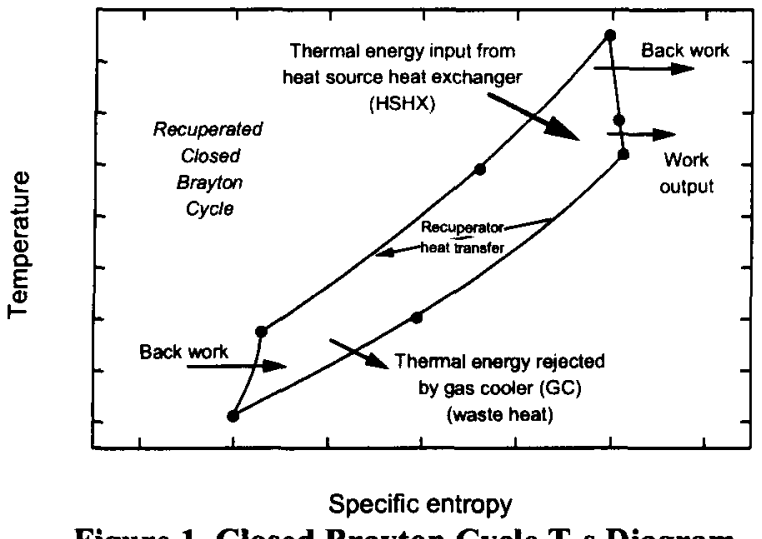

Figure 1. Closed Brayton Cycle T-s Diagram

previous detailed designs and "as-built" hardware from relevant $\mathrm{CBC}$ development programs. The comparison leads to mass and pressure-loss performance issues that are addressed in the context of the current state point reference. Directions for future work are explored; options emphasize the overall reduction of CBC PCS development risk. Finally, conclusions are drawn from the quantified performance results.

\section{STATE POINT REFERENCE}

A CBC PCS was modeled in a recent spacecraft conceptual design study performed by the National Aeronautics and Space Administration (NASA) and the Jet Propulsion Laboratory (JPL). ${ }^{3}$ The study generated a spacecraft configuration capable of completing a science mission to the icy moons of Jupiter (Callisto, Ganymede, and Europa) to search for signs of life in the oceans beneath the moons' frozen surfaces. The CBC PCS state points derived from the Jupiter Icy Moons Tour (JIMT) study are displayed with a CBC schematic in Fig. 2. These state points serve as the reference for the present assessment effort.

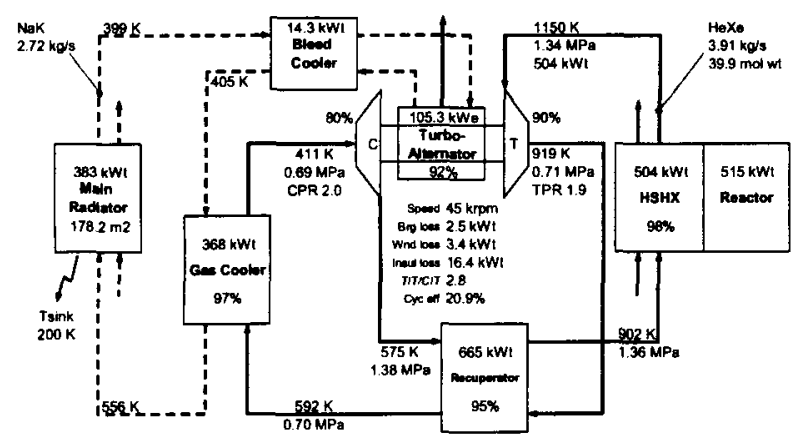

Figure 2. Closed Brayton Cycle Schematic for JIMT

\section{HEAT EXCHANGER PERFORMANCE}

Heat exchanger performance is best expressed in terms of characteristic dimensionless parameters; those parameters chosen for the present assessment include the effectiveness, $\varepsilon$, the number of transfer units, $N t u$, the relative pressure loss, $\triangle P / P$, and the entropy generation numbers, $N s$ and $N s l$. To satisfy the conditions imposed on the three $\mathrm{CBC}$ heat exchangers in Fig. 2, a combination of counterflow and multipass cross-counterflow configurations are considered. For these configurations, the development of the requisite performance-characterizing equations follows.

\section{Analytical Formulation}

Heat exchanger effectiveness is defined as

$$
\varepsilon \equiv \dot{Q}_{\text {actual }} / \dot{Q}_{\max },
$$

where the maximum heat transfer rate is determined using the minimum flow capacity rate and the largest temperature difference,

$$
\dot{Q}_{\max }=C_{\min } \Delta T_{\max }=\left(\dot{m} c_{p}\right)_{\min }\left(T_{H, \text { in }}-T_{C, \text { in }}\right) .
$$

The number of transfer units is defined using the effective conductance, $U A$, and minimum flow capacity rate,

$$
N t u \equiv U A / C_{\min } .
$$

For an adiabatic two-stream counterflow exchanger, $N t u$ is expressible in terms of $\varepsilon$ and the flow capacity ratio, ${ }^{4}$ $R_{c}\left(=C_{\min } / C_{\max }\right)$,

$$
N t u=\left(1-R_{c}\right)^{-1} \ln \left[\left(1-\varepsilon R_{c}\right) /(1-\varepsilon)\right] .
$$

When it is a balanced $\left(C_{1}=C_{2}=C\right)$ counterflow exchanger, Eq. (4) simplifies to

$$
N t u=\varepsilon /(1-\varepsilon) .
$$

In the case of a single-pass cross-flow exchanger with $C_{\max }$ unmixed and $C_{\min }$ mixed, $\varepsilon$ can be calculated ${ }^{4}$ from $N t u$ and $R_{c}$,

$$
\varepsilon=1-\exp \left[\left(e^{-R_{c} N t u}-1\right) / R_{c}\right] .
$$

Kays and London ${ }^{5}$ show that interpass mixing stipulations are not highly restricting, so Eq. (6) can be extended to multipass cross-counterflow configurations, 


$$
\varepsilon=\frac{\left[\left(1-\varepsilon_{p} R_{c}\right) /\left(1-\varepsilon_{p}\right)\right]^{k}-1}{\left[\left(1-\varepsilon_{p} R_{c}\right) /\left(1-\varepsilon_{p}\right)\right]^{k}-R_{c}},
$$

where $\varepsilon_{p}$ is the single-pass effectiveness given in Eq. (6), $k$ is the number of passes, and the total Ntu is assumed equally distributed over each pass, $N t u=k$ $N t u_{p}$. Through iteration, Eqs. (6) and (7) may be used to find the $\mathrm{Ntu}$ needed for a multipass cross-counterflow exchanger to achieve a required $\varepsilon$.

Relative pressure loss for one stream of an exchanger is given as

$$
\Delta P / P \equiv\left(P_{\text {in }}-P_{\text {out }}\right) / P_{\text {in }} .
$$

The three parameters, $\varepsilon, N t u$, and $\Delta P / P$ are widely used to classify heat exchanger performance; however, the entropy generation numbers, $N S$ and $N s I$ are far less frequently found in aerospace-related heat exchanger literature. This is unfortunate since $N s$ or $N s I$ can be extremely useful to an engineering designer considering the heat exchanger as a component of a larger thermodynamic system that one is trying to optimize. ${ }^{6-10}$ The specification of two entropy generation numbers acknowledges different methods used to nondimensionalize the entropy generation rate,

$$
N s \equiv \dot{S}_{g e n} / C_{\text {min }}
$$

and

$$
N s l \equiv T_{C, i n} \dot{S}_{g e n} / \dot{Q}_{a c t}
$$

Equation (9) uses the definition offered by Bejan; ${ }^{6}$ Eq. (10) applies the formal reference temperature modification of Hesselgraves ${ }^{11}$ to a related efficiency term from Witte and Shamsundar. ${ }^{9}$ In either definition, the entropy generation rate can be found from a general second-law statement for an open system,

$$
\dot{S}_{g e n}=\left.\frac{d S}{d t}\right|_{C V}+\int_{C S} \rho s \vec{V} \cdot \hat{n} d a+\int_{C S} \frac{\dot{q}^{n}}{T} \cdot \hat{n} d a
$$

For an adiabatic two-stream exchanger with an ideal gas flowing in both streams, the steady-state form of Eq. (11) simplifies to

$$
\begin{aligned}
\dot{S}_{\text {gen }} & =C_{1} \ln \left(T_{1, \text { out }} / T_{1, \text { in }}\right)-\dot{m}_{1} R_{1} \ln \left(P_{1, \text { out }} / P_{1, \text { in }}\right) \\
& +C_{2} \ln \left(T_{2, \text { out }} / T_{2, \text { in }}\right)-\dot{m}_{2} R_{2} \ln \left(P_{2, \text { out }} / P_{2, \text { in }}\right) .
\end{aligned}
$$

A balanced exchanger flowing the same fluid in both streams and having constant specific heat simplifies further,

$$
\begin{aligned}
\dot{S}_{\text {gen }} & =C\left[\ln \left(T_{1, \text { out }} / T_{1, \text { in }}\right)+\ln \left(T_{2, \text { out }} / T_{2, \text { in }}\right)\right] \\
& -\dot{m} R\left[\ln \left(P_{1, \text { out }} / P_{1, \text { in }}\right)+\ln \left(P_{2, \text { out }} / P_{2, \text { in }}\right)\right]
\end{aligned}
$$

If only one stream (diabatic) is considered, Eq. (11) gives (for stream number two in this case)

$$
\begin{aligned}
\dot{S}_{g e n, 2} & =C_{2} \ln \left(T_{2, \text { out }} / T_{2, \text { in }}\right) \\
& -\dot{m} R \ln \left(P_{2, \text { out }} / P_{2, \text { in }}\right)-\dot{Q}_{a c t} / T_{\text {avg }} .
\end{aligned}
$$

Finally, instead of treating only ideal gas cases, if stream one is an incompressible fluid, Eq. (11) reduces to

$$
\begin{aligned}
\dot{S}_{\text {gen }} & =\dot{m}_{1} c_{1, \text { avg }} \ln \left(T_{1, \text { out }} / T_{1, \text { in }}\right) \\
& +C_{2} \ln \left(T_{2, \text { out }} / T_{2, \text { in }}\right)-\dot{m}_{2} R_{2} \ln \left(P_{2, \text { out }} / P_{2, \text { in }}\right)
\end{aligned} .
$$

From Eqs. (13) to (15), entropy generation rates can be calculated for the configurations considered herein.

\section{Performance Analysis}

Using the temperature, pressure and fluid flow information in Fig. 2, the expected performance of the three heat exchangers may be expressed in terms of the relevant characteristic parameters. Configurations and performance parameters for the three $\mathrm{CBC}$ exchangers are discussed hereafter and summarized in Table 1.

A balanced counterflow exchanger is selected for the recuperator. Since the CBC working fluid is a helium-xenon (He-Xe) mixture and $\varepsilon$ is 0.95 , the gasgas counterflow configuration is a natural choice supported by historical precedent. The balancedexchanger values for $N t u, N s$ and $N s l$ are 19, 0.023 and 0.040 , respectively. In practice, some bleed flow from the compressor may be used for cooling different components in the system; this results in a slight flow imbalance. However, for a conceptual design study, the balanced assumption is adequate. It is worth remembering, though, that any flow imbalance will increase entropy generation and make the desired performance more difficult to achieve. The JIMT study allotted $250 \mathrm{~kg}$ for the recuperator mass. With an internal heat transfer rate of $665 \mathrm{kWt}$, this results in a mass-specific heat transfer rate of $2.7 \mathrm{kWt} / \mathrm{kg}$. In the recuperator, the pressure-loss contribution to the entropy generation rate is $114 \%$ of that due to thermal irreversibilities as indicated by a ratio of actual to isobaric Ns of 2.14. This is a noteworthy example of 
Table 1. Summary of Heat Exchanger Performance

\begin{tabular}{|c|c|c|c|c|c|c|c|c|c|c|c|c|c|c|}
\hline & Configuration Description & $\varepsilon$ & Ntu & $\begin{array}{c}\text { UA } \\
(\mathrm{kW} / \mathrm{K})\end{array}$ & $\begin{array}{c}Q^{\prime} \\
(k W)\end{array}$ & $\begin{array}{c}\text { Isobaric } \\
\text { Ns }\end{array}$ & Ns & $\frac{\mathrm{Ns}}{\mathrm{Ns}}$ & Ns1 & $\begin{array}{c}\text { mass } \\
(\mathrm{kg})\end{array}$ & $\begin{array}{c}Q^{\prime} / \mathrm{m} \\
(\mathrm{kW} / \mathrm{kg})\end{array}$ & $(\Delta \mathrm{P} / \mathrm{P})_{h}$ & $(\Delta \mathrm{P} / \mathrm{P})_{\mathrm{c}}$ & $(\triangle \mathrm{P} / \mathrm{P})_{\text {hot }}$ \\
\hline \multicolumn{15}{|l|}{ JाMT (2002) } \\
\hline Recuperator & Balanced Cntr Flow (gas-gas) & 0.95 & 19 & 38.7 & 665 & 0.011 & 0.023 & 2.14 & 0.040 & 250 & 2.66 & $2.0 \%$ & $1.0 \%$ & $3.0 \%$ \\
\hline Gas Cooler & $\begin{array}{l}\text { Unbal Cntr Flow (gas-liq) } \\
\text { Unbal 8-pass Cross-Cntr Flow (gas-liq) }\end{array}$ & 0.97 & $\begin{array}{l}11 \\
14\end{array}$ & $\begin{array}{l}22.8 \\
28.1\end{array}$ & 368 & 0.015 & 0.019 & 1.27 & 0.042 & 163 & 2.27 & $1.0 \%$ & - & - \\
\hline Heat Source HX & Undefined (gas-) " & 0.98 & - & - & 504 & 0.002 & 0.010 & 5.37 & 0.036 & 187 & 2.70 & - & $2.0 \%$ & - \\
\hline \multicolumn{15}{|c|}{ Reference Recuperators } \\
\hline SSF SD (1993) & Near-bal Cntr Flow (gas-gas) & 0.92 & 12 & 7.81 & 260 & 0.034 & 0.042 & 1.25 & 0.047 & 162 & 1.60 & $1.3 \%$ & $0.6 \%$ & $1.9 \%$ \\
\hline BRU (1972) & Near-bal Cntr Flow (gas-gas) & 0.95 & 19 & 1.69 & 46 & 0.035 & 0.050 & 1.42 & 0.040 & ** & $*$ & $2.2 \%$ & $1.1 \%$ & $3.3 \%$ \\
\hline
\end{tabular}

why an isobaric assumption can be significantly misleading in the exchanger design process.

For the gas cooler, two different configurations are considered. The coolant in both cases is liquid $\mathrm{NaK}$ with a higher flow capacity rate than the He-Xe stream. In this unbalanced state, either a counterflow or an eight-pass cross-counterflow option will yield the necessary $\varepsilon$ of 0.97 . Since the state-point, top-down system design approach yields entropy generation numbers that are not configuration-specific, $N s$ and $N s I$ are 0.019 and 0.042 , respectively, for both options. The counterflow exchanger yields a lower $\mathrm{Ntu}(11$ versus 14), but other factors must be considered before a configuration is selected. For instance, to reach the stated effectiveness, a plate-fin counterflow exchanger might appear an attractive choice. However, manufacturing techniques used to assemble certain plate-fin configurations sometime create small internal leaks between flow streams. Migration of $\mathrm{NaK}$ into the CBC working fluid could be catastrophic for the engine. Therefore, despite the higher Ntu, a multipass crosscounterflow exchanger placing only finned tubes in the He-Xe stream might be selected to reduce the likelihood of leakage and thereby improve system reliability. With an allotted mass of $163 \mathrm{~kg}$ and required transfer of $368 \mathrm{kWt}$, the GC mass-specific requirement is $2.3 \mathrm{kWt} / \mathrm{kg}$.

The HSHX configuration is highly dependent on the method used to remove thermal energy from the fission reactor core. Feasible cooling methods are direct-gas feed, heat-pipes or a pumped liquid metal loop. A gas-cooled reactor may route the $\mathrm{CBC}$ working fluid directly through the core. A very different heat exchange interface between the reactor and the CBC PCS will be required for reactor cooling schemes using heat pipes or a pumped loop. Due to continued uncertainty in the allowable configurations, only the CBC flow stream is evaluated at present. The singlestream heat transfer requirement gives a required $\varepsilon$ of 0.98 for the interface when the reactor output is $515 \mathrm{kWt}$. Entropy generation for the single stream is calculable $(N s=0.010, N s I=0.036)$, but the lack of interface definition prohibits the reporting of $N t u$ values. An HSHX specific heat transfer rate of $2.7 \mathrm{kWt} / \mathrm{kg}$ is needed.

\section{HISTORICAL COMPARISON}

With JIMT performance objectives identified for the CBC heat exchangers, a review of relevant historical data can lend perspective to a system feasibility assessment. Serving as an example, focus will be placed on the recuperator due, at least in part, to high confidence in the available reference data.

Performance data for reference recuperators appear as the last three entries in Table 1. One entry gives data from a detailed design study and the other data represent "as-built" pieces of hardware from $\mathrm{CBC}$ development programs.

The Solar Dynamic Power System designed for Space Station Freedom ${ }^{12}$ (SSF SD) provides a preliminary design of a plate-fin, gas-gas counterflow heat exchanger with an $\varepsilon$ of 0.94 under nominal system operating conditions and 0.92 for maximum $\dot{Q}$. The maximum $\dot{Q}$ condition is selected for comparison. In the 36-kWe CBC system, the recuperator design incorporates offset fins in the counterflow section and plain rectangular fins in the triangular end sections. A $\mathrm{He}-\mathrm{Xe}$ mixture with molecular weight of 40 is the working fluid. The design utilizes corrosion-resistant steel (CRES) 304L and calls for a nickel-alloy braze assembly process.

The recuperator in the $2-\mathrm{kWe}$ mini-BraytonRotating-Unit (miniBRU) CBC system ${ }^{13}$ is also a platefin, gas-gas counterflow heat exchanger that uses offset fins in the core and rectangular fins in triangular transition areas. It was fabricated using Hastelloy $X$ and a multiple-step brazing technique. After fabrication, the unit was performance tested using natural gas combustion products on the hot side and air on the cold side. Test measurements were analytically scaled to predict performance for operation in an 83.8 molecular weight $\mathrm{He}-\mathrm{Xe}$ mixture.

The miniBRU was a smaller version of the $6 \mathrm{kWe}$ (nominal) Brayton Rotating Unit (BRU) that combined 
a recuperator and gas-cooler into the Brayton Heat Exchanger Unit ${ }^{13,14}$ (BHXU) for the CBC system. The BHXU plate-fin, gas-gas counterflow recuperator was fabricated using 347 series stainless steel. The recuperator core mass was $91 \mathrm{~kg}$, but a total mass for the recuperator alone was not reported due to the integral assembly with the GC.

In comparing JIMT recuperator performance with the three reference cases, one observes that JIMT calls for the highest overall heat transfer rate. At $665 \mathrm{kWt}$, the JIMT recuperator requires 2.5 times the $\dot{Q}$ of the largest of the three reference recuperators (SSF SD). Fortunately, the JIMT flow capacity rate is 1.6 times larger as well. However, the dimensionless comparison is more meaningful because it shows that, despite the increased flow capacity, the higher $\varepsilon$ for JIMT leads to a larger $N i u$ than that of the SSF SD recuperator. The related dimensional result is that the JIMT $U A$ of $38.7 \mathrm{~kW} / \mathrm{K}$ is the largest listed. Since achievable $U$ for a gas-gas exchanger is usually limited by per-length pressure-loss constraints, increasing $A$ (and the size of the exchanger), is often how $U A$ performance is obtained. This was the design approach used for the MiniBRU recuperator $(\varepsilon=0.98, N t u=40)$, where a low mass flow rate allowed the fluid to be exposed to a large heat transfer surface while still maintaining very low relative pressure losses $\left(\Delta P / P_{\text {total }}=0.8 \%\right)$. Since MiniBRU was a development program (ground test only), mass and volume constraints were considered but were not highly restrictive. For a flight system needing much higher mass flow rates, a similar approach may be less rewarding.

One method of examining the relative thermodynamic difficulty of constructing the recuperators is by comparing entropy generation numbers. When using $N s 1$ to rate the entropy generation rate per unit of heat transfer at a specified cold-streaminlet temperature, the JIMT case appears to be similar to previous designs. An Nsl range of 0.040 to 0.047 captures all but the MiniBRU recuperator; the MiniBRU has the least irreversibility $(N s I=0.016)$ using this relative measure. However, even though the MiniBRU recuperator has more demanding values for $\varepsilon$ and $\mathrm{Ntu}$, the slightly lower $\mathrm{Ns}$ of JIMT shows that fewer irreversibilities are allowed per flow capacity rate in the JIMT case. This irreversibility restriction is highlighted by comparing the JIMT and BRU recuperators across all parameters. These two exchangers are nearly identical in dimensionless definition $(\varepsilon=0.95, \mathrm{Ntu}=$ $\left.19, \Delta P / P_{\text {total }} \cong 3 \%, N s I=0.040\right)$ except that the JIMT recuperator is held to one-half the total entropy generation per flow thermal capacity. In light of the large pressure-loss contribution to entropy generation noted $\left(N s / N s_{\text {isobaric }}=2.14\right)$, this observation may suggest that the pressure-loss allotment is too confining in the current JIMT cycle design. This issue is further examined using the more detailed pressure-loss and mass estimates that follow.

\section{PRELIMINARY DESIGN ESTIMATES}

The JIMT mass allotments shown in Table 1 are estimated using empirical "performance and sizing" curve fits resident in a large-scale PCS optimization code. The system analysis code is used as a conceptual design tool that yields preliminary component requirements. To further evaluate the feasibility of meeting the requirements, more detailed analysis tools are used.

Using a design algorithm developed at the NASA Glenn Research Center, preliminary heat exchanger mass and pressure-loss estimates can be determined once thermal performance parameters are established. The algorithm is built upon fundamental heat-transfer and fluid-flow principles and its power-law scaling routines are anchored by historical performance datain this case for metallic plate-fin counterflow heat exchangers. Uncertainty in available heat-transfer and pressure-loss correlations is addressed in the algorithm by calculating maximum and minimum estimates that use the extreme range of the proposed values for the variables in question (often correlation exponents). For counterflow recuperators, the design code assumes balanced flow conditions, so, as noted earlier, any imbalance will increase the entropy generation rate and degrade performance.

Mass and pressure-loss estimates for the JIMT case of Fig. 1 are displayed in Table 2. The system optimization allotments are also presented. The allotted values fall below the minimum estimates from the design algorithm. This suggests that, using conventional technology (a requisite of the historical anchor in the algorithm), a recuperator that satisfies the thermal performance objectives derived from Fig. 2 will exceed the associated mass and pressure-loss targets.

The discrepancy between the sizing curve fits and the heat exchanger design algorithm is explained from the fact that the empirical data on which the curve fits are based do not include an exchanger in this performance category; the JIMT combination of high $\varepsilon$,

Table 2. Mass and Pressure-Loss Data

\begin{tabular}{lcccc}
\hline & mass & & \\
& $(\mathrm{kg})$ & $(\Delta \mathrm{P} / \mathrm{P})_{\mathrm{h}}$ & $(\Delta \mathrm{P} / \mathrm{P})_{\mathrm{c}}$ & $(\Delta \mathrm{P} / \mathrm{P})_{\mathrm{tot}}$ \\
\hline JIMT Allotments & 250 & $2.0 \%$ & $1.0 \%$ & $3.0 \%$ \\
Minimum Design Estimates & 287 & $2.7 \%$ & $1.3 \%$ & $4.0 \%$ \\
Maximum Design Estimates & 565 & $7.3 \%$ & $2.5 \%$ & $9.9 \%$ \\
\hline \hline
\end{tabular}


very low $N s$ and large specific heat transfer $(\dot{Q} / \mathrm{m})$ is outside the empirical database. Therefore, the sizing values are extrapolated from the empirical curves. In contrast, even though the design algorithm is anchored with the same historical data, the algorithm is based on fundamental principles, so its ability to scale to the higher performance case is better. For example, Fig. 3 shows that near the experience range, mass estimates from the empirical fit and the design algorithm agree to within $5 \%$. But outside the historical database (emulated here by elevating $\varepsilon$ at high $\dot{Q}$ ), Fig. 4 reveals a major difference between algorithm and empirical estimates. Indeed, in the extreme case as $\varepsilon$ approaches 1.0 , the empirical fit will give a finite mass estimate whereas the algorithm yields the correct (but impalpable) trend to an infinitely large exchanger; this behavior is illustrated in Fig. 5.

Therefore, relying on design algorithm output, the predictions indicate that expectations of $\mathrm{CBC}$ heat exchangers in a $100-\mathrm{kWe}$ PCS are high. The challenge of achieving needed performance (represented by JIMT allotted values) must be addressed.

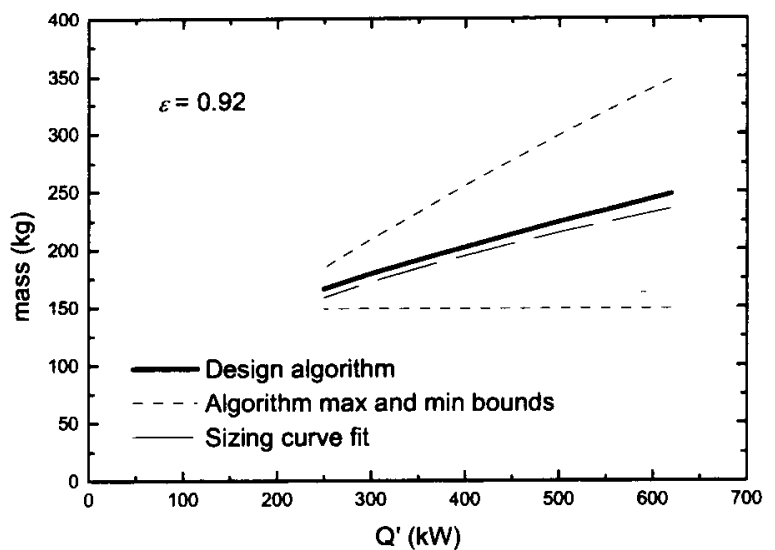

Figure 3. Estimates Agree Near Experience Range

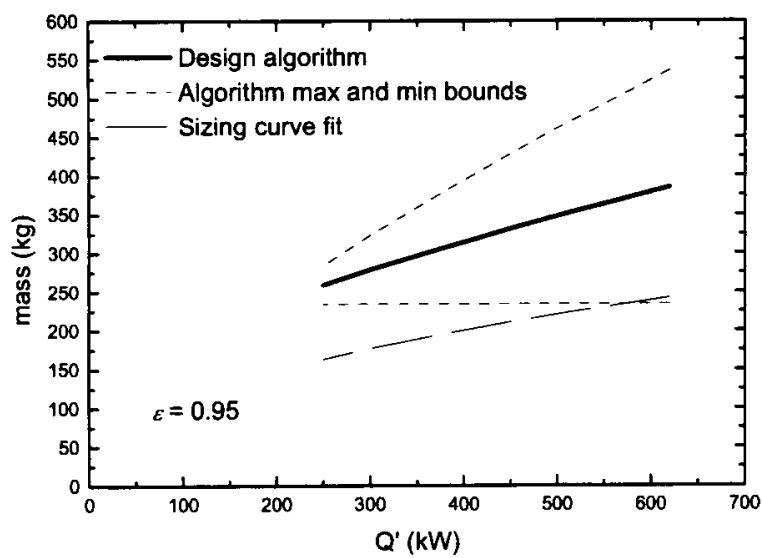

Figure 4. Estimates Differ Outside Historical Database

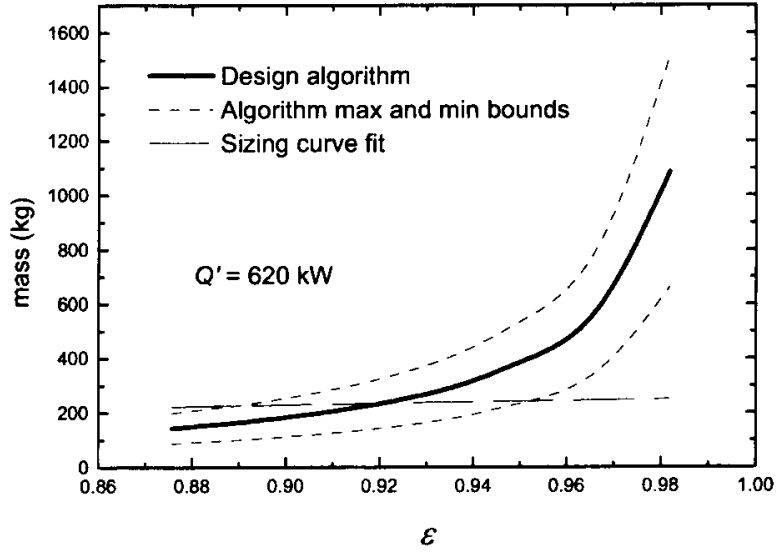

Figure 5. Correct High- $\varepsilon$ Trend in Algorithm

\section{PERFORMANCE/DEVELOPMENT OPTIONS}

To advance the state-of-the-art such that $100-\mathrm{kWe}$ class CBC heat exchanger targets are easily reached, at least three options can be examined. Options include altering cycle state points to reduce heat exchanger performance expectations, enhancing heat transfer in exchangers fabricated from conventional materials, and incorporating advanced materials in exchangers to reduce mass while improving heat transfer.

Because the forecast expectations are demanding, seeking less restrictive CBC state points is a logical approach to finding an easier heat exchanger solution. The cycle thermodynamics can be modified so that lesser performance is needed from the heat exchangers, however, overall cycle performance will degrade. Additionally, reworking the cycle analysis to provide relief for the exchangers will place added performance demands on other power system components such as the heat rejection radiators and the heat source. Simply shifting the burden from one component to another does not guarantee an increase in overall design feasibility. This option must be investigated at the system levelfocusing on impacts to overall system performance. Preliminary analyses indicate minor penalties exist.

Design techniques used to augment mass-specific heat transfer rates in conventional (metallic) exchangers include geometric surface enhancement, constructal formulation, ${ }^{15,16}$ and material coating application. Any method that increases pressure-loss in addition to heat transfer (as is typical) must be evaluated closely because, as Tables 1 and 2 indicate, managing the allocated pressure loss is already difficult. The ratio of augmented-to-baseline entropy generation numbers, $\mathrm{Ns}_{\text {augmented }} / \mathrm{Ns}_{\text {baseline, }}$, is a useful parameter to consider when evaluating the success of any of the listed enhancement approaches; ratios less than one are thermodynamically desirable. 
Finally, adopting advanced materials for the construction of exchanger components may reduce mass and simultaneously enhance heat transfer performance. A promising candidate with recent technology development activity is carbon-carbon (C-C) material. The Air Force $^{17}$ and $\mathrm{Navy}^{18}$ have examined C-C sheeting and foam for heat exchanger plate-fin and plate-foam configurations. Compared to metallic superalloys, the increased thermal conductivity coupled with the decreased density of the $\mathrm{C}-\mathrm{C}$ material enables lighter exchanger passages with reduced thermal resistance (increased conductance). Figure 6 shows single-layer finned and foamed exchanger passage test articles from reference [18]. The Air Force study reported a $40 \%$ mass reduction (compared to a nickelbased alloy) using a $\mathrm{C}-\mathrm{C}$ core in a plate-fin exchanger.

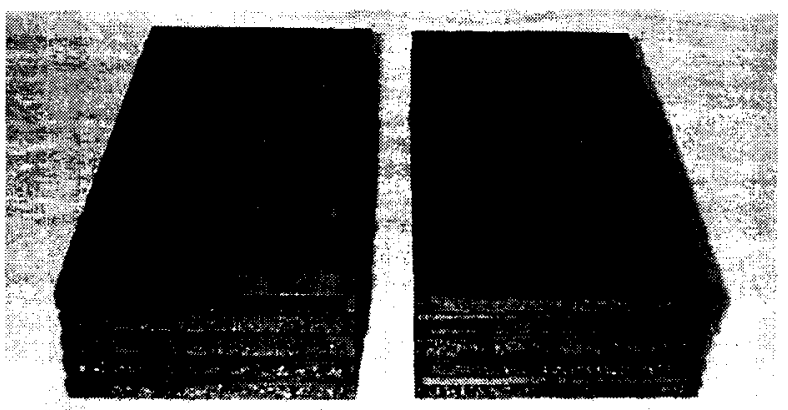

Figure 6. Carbon-Carbon Test Sections From [18]

Development problems associated with $\mathrm{C}-\mathrm{C}$ core construction include oxidation, mismatched thermal expansion, and inter-passage leakage. Surface oxidation reduces the heat transfer capability of the material. For typical aircraft applications, the presence of air as a working fluid necessitates the application of surface coatings to reduce oxidation at high temperatures. Fortunately, the He-Xe working fluid in a space CBC PCS is inert and relegates the threat of internal oxidation to a fabrication and ground-processing issue.

Integrating a $\mathrm{C}-\mathrm{C}$ core into an otherwise metallic exchanger introduces thermal expansion concerns. Because of mismatched coefficients of thermal expansion between the $\mathrm{C}-\mathrm{C}$ and a metallic header pipe or housing, improper design of the interface can lead to excessive thermal stresses. Flexible attach points or the development of C-C headers have been proposed to correct this problem.

To reduce inter-passage leakage, development efforts have focused on improved brazing techniques and assembly methods. ${ }^{19}$ The insertion of thin metallic foil between C-C sections is also being explored. Preliminary analyses indicate that overall improved thermal performance would still be maintained with the

lower conductivity foil and C-C combination as compared to a conventional superalloy design.

\section{CONCLUSIONS}

Performance expectations of closed-Brayton-cycle heat exchangers in a $100-\mathrm{kWe}$ space power conversion system are demanding. Preliminary design results indicate that component mass and pressure-loss aspirations are difficult to achieve using conventional exchanger technology. A traditional recuperator design exceeds the mass target by at least $15 \%$ and the total allocated pressure-loss by $33 \%$. Pressure-loss adds significantly to the entropy generation rate; the largest relative frictional contribution is $114 \%$ of the heattransfer irreversibility. The allowable entropy generation number, $N s=0.023$, is $12 \%$ lower than the lowest value previously demonstrated in a higheffectiveness, closed-Brayton-cycle recuperator.

Two gas-cooler configurations satisfy the effectiveness requirements of a $100-\mathrm{kWe}$-class system. A gas-liquid exchanger in either a single-pass counterflow or an eight-pass cross-counterflow arrangement supplies the 0.97 effectiveness needed. To reduce the likelihood of liquid migration into the working fluid and thereby improve system reliability, the cross-counterflow design, although having a larger $\mathrm{Ntu}$, is a viable candidate.

There exist several practical options to reduce the heat exchanger contribution to overall system development risk. Modifying cycle operating points, using enhanced heat transfer techniques, and incorporating advanced materials in the exchangers are all possibilities. The application of carbon-carbon sheeting or foam in the construction of exchanger core passages is a particularly attractive option due to the relatively mature level of technology readiness.

$a$

A c

C $k$ $m$ $n$ Ns

Ns1

$P$

$\dot{Q}$

$R$

$S$

$S$

\section{NOMENCLATURE}

surface area

total heat transfer area on one side of exchanger specific heat

flow thermal capacity rate $\left(=\dot{m} c_{p}\right)$ number of passes in a multipass configuration mass

outward unit normal

entropy generation number $\left(=\dot{S}_{g e n} / C_{\text {min }}\right)$ entropy generation number $\left(=T_{C, \text { in }} \dot{S}_{\text {gen }} / \dot{Q}_{a c t}\right)$ absolute pressure

heat transfer rate

gas constant

specific entropy

total entropy 
$T$ absolute temperature

$U$ overall heat transfer coefficient based on area $A$

$V \quad$ velocity

\section{Greek}

$\varepsilon \quad$ effectiveness

$\rho$ density

\section{Subscripts}

\begin{tabular}{ll}
\hline 1 & flow stream one \\
2 & flow stream two \\
$C$ & cold stream \\
$C V$ & control volume \\
$C S$ & control surface \\
gen & generation \\
$H$ & hot stream \\
$p$ & for a single pass
\end{tabular}

\section{Superscripts}

- time rate of change

" per unit area

\section{REFERENCES}

1. Weiler, E.J., 2003, "Statement of Dr. Edward J. Weiler, Associate Administrator, Office of Space Science, National Aeronautics and Space Administration," Before the U.S. Senate Committee on Commerce, Science, and Transportation: Subcommittee on Science, Technology, and Space, Hearing on Space Propulsion, 108th Congress, 1st Session, June 3, 2003. (Available from the internet at: http://legislative.nasa.gov/hearings/weiler6-3..pdf)

2. Shaltens R.K., and Mason, L.S., 1996, "Early Results from Solar Dynamic Space Power System Testing," AIAA Journal of Propulsion and Power, 12, No. 5, pp. 852-858.

3. Mason, L.S., 2003, “A Power Conversion Concept for the Jupiter Icy Moons Orbiter," Proceedings of the lst International Energy Conversion Engineering Conference, Portsmouth, VA, AIAA2003-6007.

4. Mills, A.F., 1999, Heat Transfer, 2nd Ed., Prentice Hall, p.791.

5. Kays, W.M, and London, A.L., 1964, Compact Heat Exchangers, 2nd Ed., McGraw-Hill, pp. 20-21.

6. Bejan, A., 1977, "The Concept of Irreversibility in Heat Exchanger Design: Counterflow Heat Exchangers for Gas-to-gas Applications," ASME Journal of Heat Transfer, 99, pp. 374-380.
7. Bejan, A., 1978, "General Criterion for Rating Heatexchanger Performance," International Journal of Heat and Mass Transfer, 21, pp. 655-658.

8. Bejan, A., 1980, "Second Law Analysis in Heat Transfer," Energy, 5, pp. 721-732.

9. Witte, L.C., and Shamsundar, N., 1983, "A Thermodynamic Efficiency Concept for Heat Exchange Devices," ASME Journal of Engineering for Power, 105, pp. 199-203.

10. Witte, L.C., 1988, "The Influence of Availability Costs on Optimal Heat Exchanger Design," ASME Journal of Heat Transfer, 110, pp. 830-835.

11. Hesselgraves, J.E., 2001, Compact Heat Exchangers: Selection, Design, and Operation, 1st Ed., Pergamon Press, p. 97.

12. Staff, Solar Dynamic Power System Branch, 1993, "Solar Dynamic Power System for Space Station Freedom," NASA Reference Publication 1310, NASA Lewis Research Center, Cleveland, $\mathrm{OH}$.

13. Killackey, J.J., Graves, R., and Mosinskis, G., 1978, "Design and Fabrication of the Mini-Brayton Recuperator (MBR)," NASA CR-159429, NASA Lewis Research Center, Cleveland, $\mathrm{OH}$.

14. Davis, J.E., 1972, "Design and Fabrication of the Brayton Rotating Unit," NASA CR-1870, NASA Lewis Research Center, Cleveland, $\mathrm{OH}$.

15. Vargas, J.V.C., Bejan, A., and Siems, D.L., 2001, "Integrative Thermodynamic Optimization of the Crossflow Heat Exchanger for an Aircraft Environmental Control System," ASME Journal of Heat Transfer, 123, pp. 760-769.

16. Bejan, A., 2002, "Dendritic constructal heat exchanger with small-scale crossflows and largerscales counterflows," International Journal of Heat and Mass Transfer, 45, pp. 4607-4620.

17. Stevenson, R.D., Vrable, D.L., and Watts, R.J., 1999, "Development of an Intermediate Temperature Carbon-carbon Heat Exchanger for Aircraft Applications," Proceedings of the 44th International SAMPE Symposium, 44(2), pp. 1888-1897.

18. Vrable, D.L., and Shih, W., 2002, "Experimental Measurements of Heat Transfer and Pressure Drop Characteristics for Carbon Foams," 26th Annual Conference on Composites, Materials and Structures, Cocoa Beach, FL.

19. Kearns, K.M., Anderson, D.P., and Watts, R., 1999, "Brazing of Carbon-carbon for An Aircraft Heat Exchanger," Proceedings of the 44th International SAMPE Symposium, 44(2), pp. 1898-1908. 


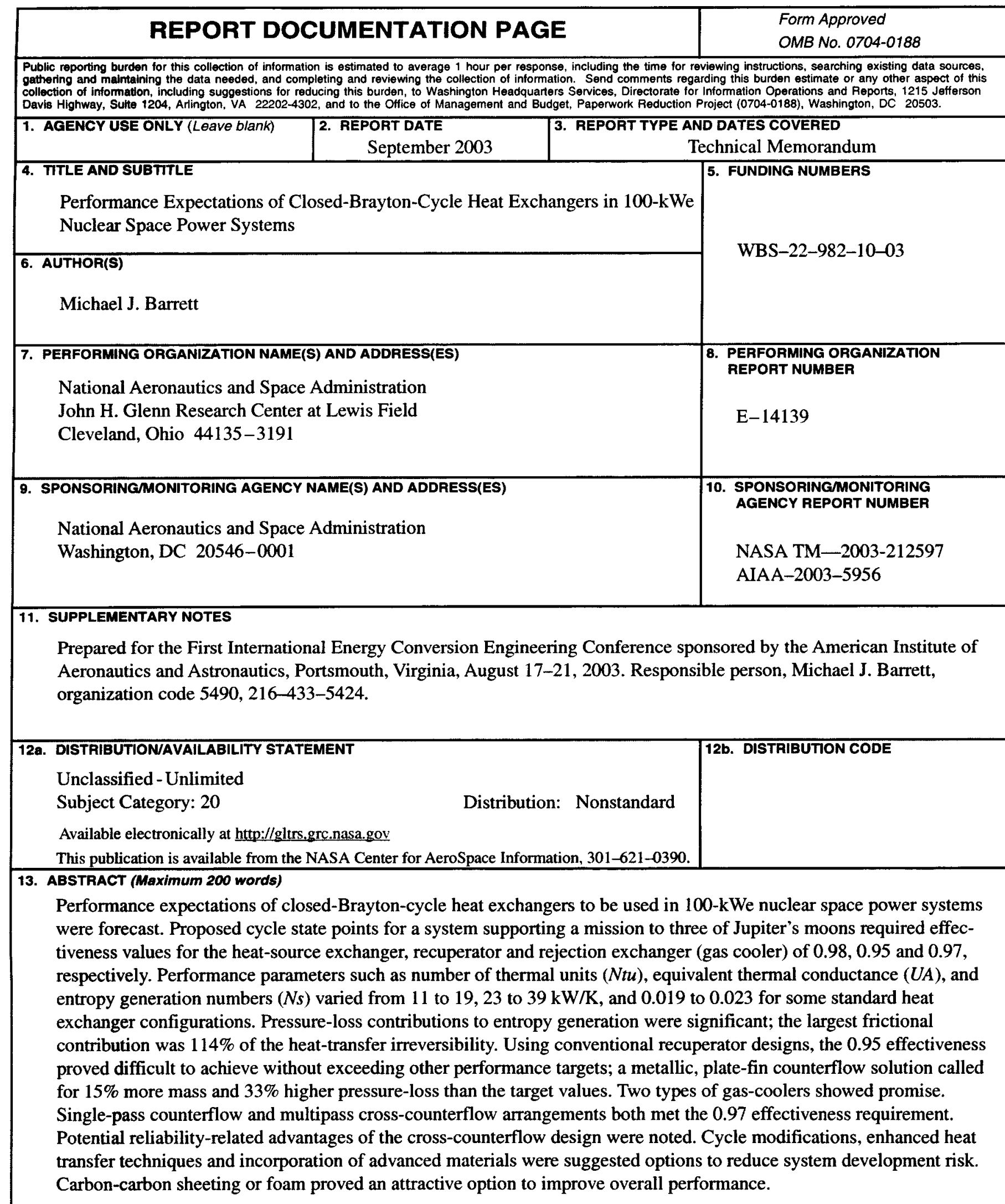

\section{SUBJECT TERMS}

Heat exchangers; Closed cycles; Nuclear electric power generation; Turbogenerators 14

\begin{tabular}{|c|c|c|}
\hline $\begin{array}{c}\text { 17. SECURITY CLASSIFICATION } \\
\text { OF REPORT } \\
\text { Unclassified }\end{array}$ & $\begin{array}{c}\text { 18. SECURITY CLASSIFICATION } \\
\text { OF THIS PAGE } \\
\text { Unclassified }\end{array}$ & $\begin{array}{c}\text { 19. SECURITY CLASSIFICATION } \\
\text { OF ABSTRACT } \\
\text { Unclassified }\end{array}$ \\
\hline
\end{tabular}

NSN 7540-01-280-5500 